\title{
THE SEAL OF THE CAMBRIDGE ENTOMOLOGICAL CLUB
}

By A. P. Morse, Wellesley, Mass.

[The following note concerning the seal recently adopted by the Club has been supplied by A. P. Morse to whom we are indebted, not only for the design, but also for its artistic execution in the final form which appears on the cover of the present issue of Psyche. Editor]

The Cambridge Entomological Club has always recognized New England as its special and appropriate tho not exclusive field of activity. It is, therefore, fitting that a typically New England insect, the Semidea butterfly, whose habitat is the alpine zone of the Presidential Range of the White Mountains of New Hampshire, should be chosen for representation on its Club Seal.

The insect is here shown perched characteristically on the dark gray, deeply weather-bitten rock-fragments of its mountain home, whose tints and texture its own so closely resemble, that when lying on its side with wings closed to escape the wind it becomes almost invisible. Beyond it at the right is suggested the sedgy slope of "Semidea plateau" (so christened by Scudder) with its rock-rivulets in whose crannies the butterfly often seeks shelter from the furious blasts which sweep over the summits even in midsummer. Beyond, from the depths of the Great Gulf, rise the slopes of the northern peaks, Mts. Jefferson, Adams, and Madison, with Mt. Washington suggested at the left. Over all float the summer clouds which often shroud the summit of Washingion for days at a time even when the other peaks are free. 

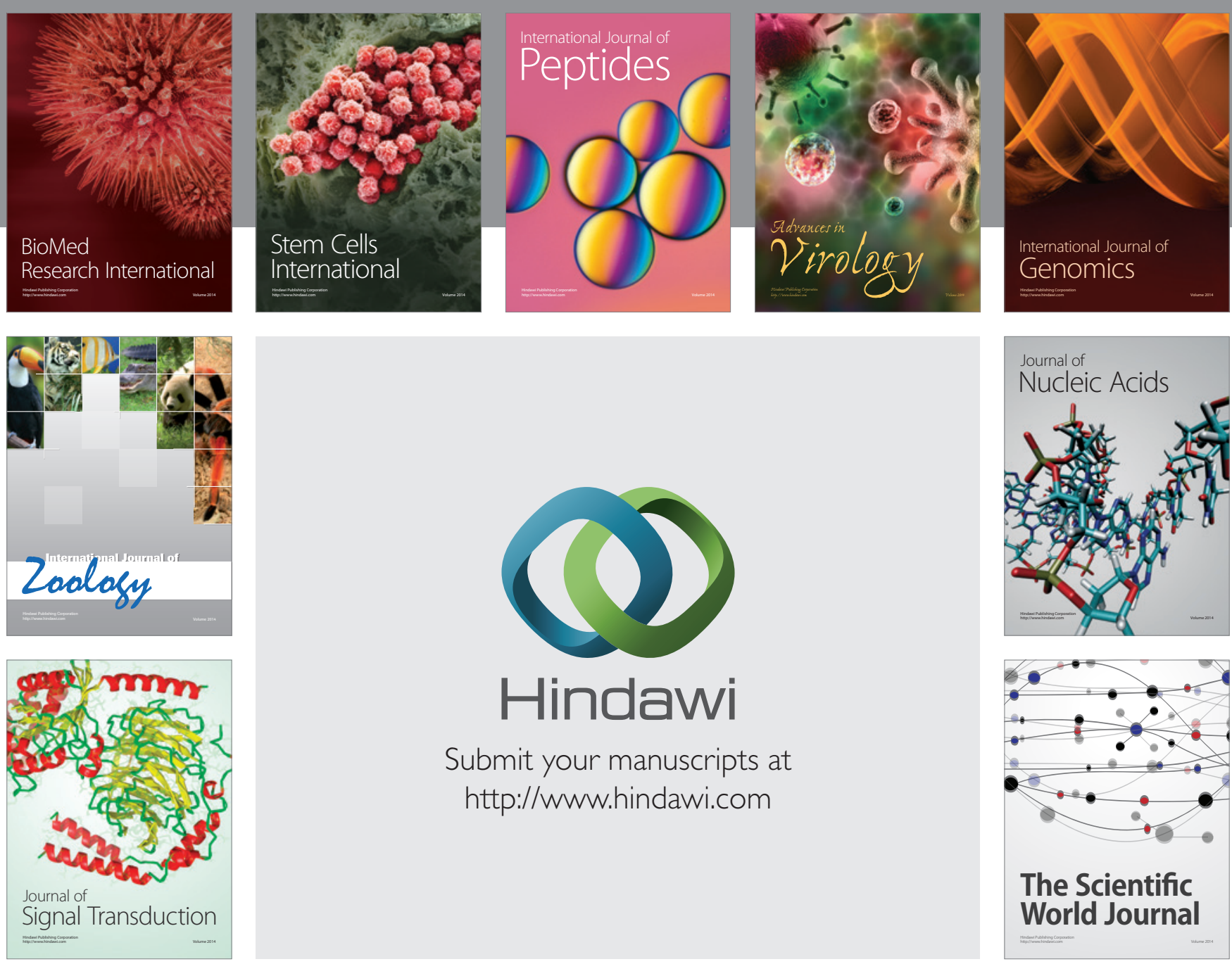

Submit your manuscripts at

http://www.hindawi.com
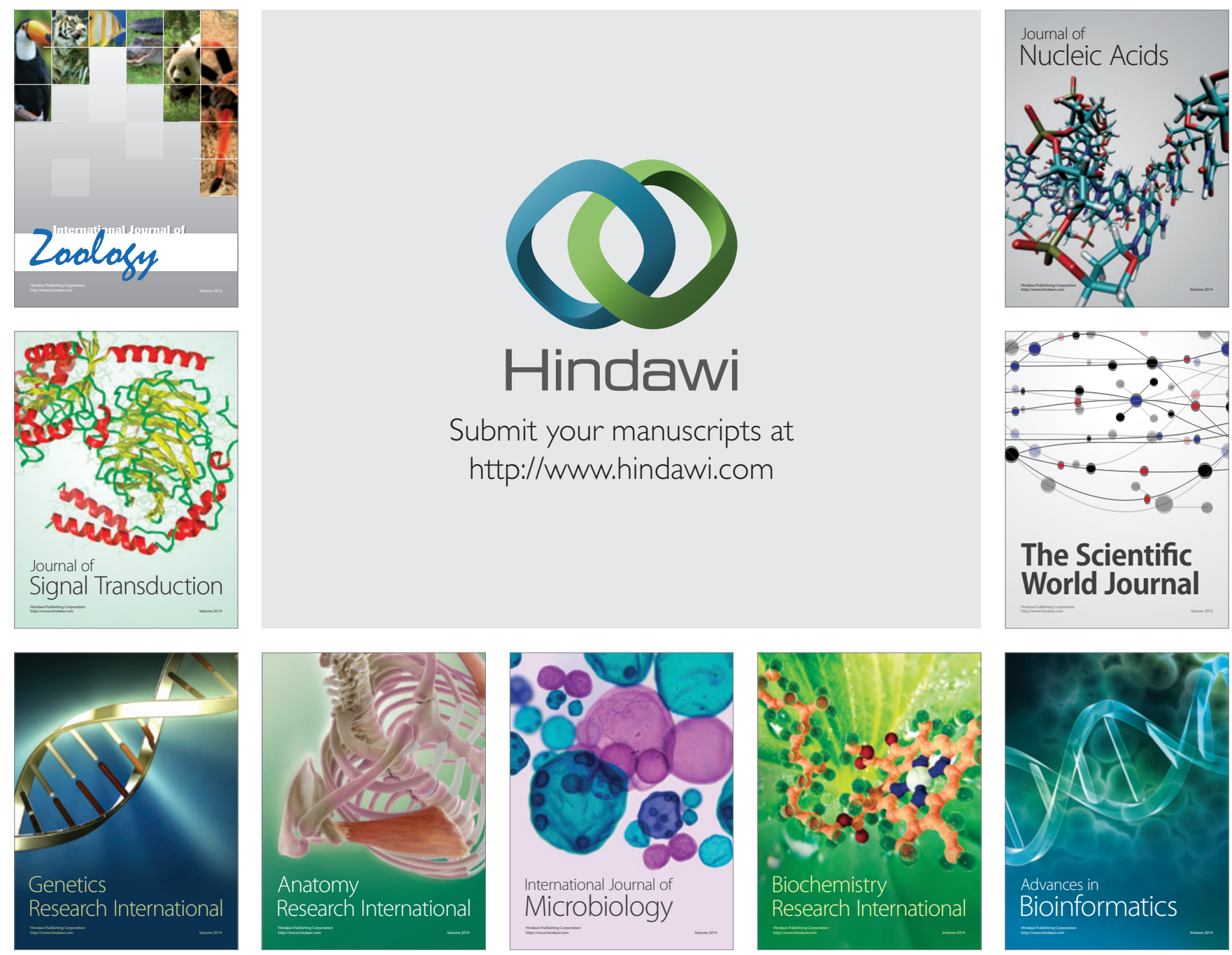

The Scientific World Journal
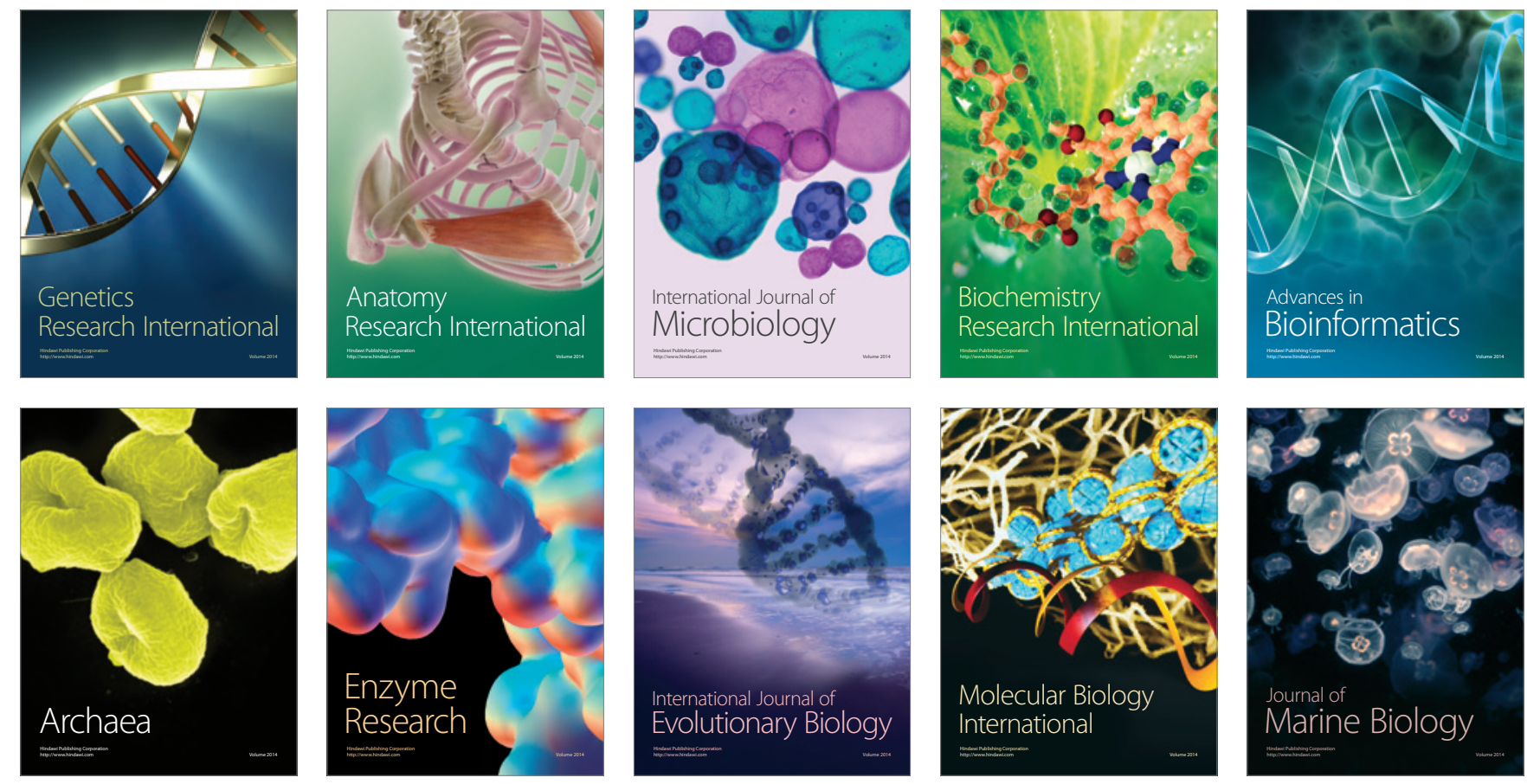